\title{
Association between Aortic Atheroma and Cerebral Small Vessel Disease in Patients with Ischemic Stroke
}

\author{
Tae-Jin Song, , , Young Dae Kim, ${ }^{\mathrm{b}}$ Joonsang Yoo, ${ }^{\mathrm{b}}$ Jinkwon Kim, ${ }^{\mathrm{b}, \mathrm{c}}$ Hyuk-Jae Chang, ${ }^{\mathrm{d}}$ Geu Ru Hong, ${ }^{\mathrm{d}}$ \\ Chi Young Shim, ${ }^{\mathrm{d}}$ Dongbeom Song, ${ }^{\mathrm{b}}$ Ji Hoe Heo, ${ }^{\mathrm{b}}$ Hyo Suk Nam ${ }^{\mathrm{b}}$ \\ aDepartment of Neurology, Ewha Womans University College of Medicine, Seoul, Korea \\ ${ }^{b}$ Department of Neurology, Yonsei University College of Medicine, Seoul, Korea \\ 'Department of Neurology, Cha University College of Medicine, Seongnam, Korea \\ ${ }^{d}$ Department of Cardiology, Yonsei University College of Medicine, Seoul, Korea
}

\begin{abstract}
Background and Purpose Cerebral small vessel disease (SVDs) are related with large artery atherosclerosis. However, the association between aortic atheroma (AA) and cerebral small vessel disease has rarely been reported. This study evaluated the relationship between presence and burden of AAs and those of SVDs in patients with acute ischemic stroke.

Methods We included 737 consecutive patients who underwent transesophageal echocardiography (TEE) and brain magnetic resonance imaging (MRI) for evaluation of acute stroke. AA subtypes were classified as complex aortic plaque (CAP) and simple aortic plaque (SAP). Presence and burden of SVDs including cerebral microbleeds (CMBs), white matter hyperintensities (WMHs), perivascular spaces (PVSs), asymptomatic lacunar infarctions (ALIs), and total SVD score, were investigated.

Results AA was found by TEE in 360 (48.8\%) patients including $11.6 \%$ with CAP and $37.2 \%$ with SAP. One or more types of SVDs was found in $269(36.4 \%)$ patients. In multivariable analysis, presence of CMBs (odds ratio [OR] 4.68), high-grade WMHs (OR 3.13), high-grade PVSs (OR 3.35), and ALIs (OR 4.24) were frequent in patients with AA than those without AA. Each 1-point increase in total SVD score increased the odds of presence of CAP (OR 1.94, 95\% confidence interval (CI) 1.441.85) and SAP (OR 1.54, 95\% Cl 1.35-1.75).

Conclusions In this study, patients with AA frequently had cerebral SVDs. Larger burden of AA was associated with advanced cerebral SVDs. Our findings give an additional information for positive relationship with systemic atherosclerosis and coexisting cerebral SVDs in acute ischemic stroke patients.
\end{abstract}

\author{
Correspondence: Hyo Suk Nam \\ Department of Neurology, Yonsei \\ University College of Medicine, \\ 50-1 Yonsei-ro, Seodaemun-gu, Seoul \\ 03722, Korea \\ Tel: $+82-2-2228-1617$ \\ Fax: +82-2-393-0705 \\ E-mail: hsnam@yuhs.ac
}

Received: March 5, 2016

Revised: June 1, 2016

Accepted: June 2, 2016

\begin{abstract}
This work was supported by a grant from the Korea Healthcare Technology Research and Development Project, Ministry for Health, Welfare, and Family Affairs, Republic of Korea (HI08C2149), a faculty research grant from Yonsei University College of Medicine for 2015 (6-20150158), and the Basic Science Research Program through the National Research Foundation of Korea funded by the Ministry of Education (2015R1D1A1A01057934).

The authors have no financial conflicts of interest.
\end{abstract}

Keywords Aortic atheroma; Cerebral small vessel diseases; White matter hyperintensity

\section{Introduction}

Aortic atheroma $(\mathrm{AA})$ is an atherosclerotic change in proximal and distal aorta or aortic arch. AA is regarded as high risk for occurrence and recurrence of ischemic stroke and poor long-term outcomes. ${ }^{1,2}$ Association between AA and cerebral large artery atherosclerosis had been confirmed not only in pathologic studies $^{3}$ but also in clinical studies in patients with ischemic stroke. ${ }^{4,5}$
Transesophageal echocardiography (TEE) is a useful tool for identification of AA. Presence of AA may indicate the presence of atherosclerosis in other vascular beds. ${ }^{4}$

Cerebral small vessel diseases (SVDs) including cerebral microbleeds (CMBs), white matter hyperintesities (WMHs), perivascular spaces (PVSs) and asymptomatic lacunar infarctions (ALIs) are associated with both ischemic and hemorrhagic stroke. ${ }^{6,7}$ Like AA, these SVDs had been reported that association of recurrence 
and progression of ischemic stroke. ${ }^{8}$

Patients with either AAs or SVDs frequently have common vascular risk factors including old age and hypertension. ${ }^{9,10}$ Apart from the association with stroke risk factors, AAs are known to make injury to brain via direct (such as embolic ischemic damage) and/or indirect mechanism (such as increased arterial stiffness by AAs). ${ }^{11,12}$ Even though many studies reported the association between large artery atherosclerosis and SVDs, ${ }^{13}$ the studies for the relationship between AA and SVDs are limited. ${ }^{14}$ In this regards, we intended to investigate the relationship between presence and burden of AAs and those of coexisting SVDs in patients with acute ischemic stroke.

\section{Methods}

\section{Subjects}

Subjects for this study were drawn from consecutive patients with acute ischemic stroke who were registered in the Yonsei Stroke Registry. ${ }^{15}$ The Yonsei Stroke Registry is a prospective hospital-based registry of patients with cerebral infarction or transient ischemic attack within 7 days after symptom onset. ${ }^{16}$ During admission, all patients were evaluated according to the standard stroke evaluation that includes brain imaging (computed tomography and/or magnetic resonance imaging [MRI]), vascular imaging studies (digital subtraction angiography, MR angiography, or computed tomography angiography), plain chest X-ray, 12-lead electrocardiography and cardiac echocardiography including TEE. Stroke subtype was determined according to the Trial of Org 10172 in Acute Stroke Treatment (TOAST) classification. ${ }^{17,18}$ Briefly, large artery atherosclerosis is defined as significant ( $\geq 50 \%$ ) stenosis of the large artery relevant to the acute infarction. The presence of complex aortic plaque (CAP) was considered as one form of large artery atherosclerosis. Cardioembolism is defined as at least one potential cardiac source of embolism based on the TOAST classification. A patient with lacunar infarction should have one of the classic clinical lacunar syndromes and a relevant subcortical hemispheric or brain stem lesion with diameter $<1.5 \mathrm{~cm} .{ }^{16}$ Besides above method of the TOAST classification, we reclassified the TOAST classification. In that reclassification, CAPs were not considered as large artery atherosclerosis. The Institutional Review Board of Severance Hospital, Yonsei University Health System, approved this study and waived the need for patient informed consent because of the retrospective design and observational nature of the study.

\section{Transesophageal echocardiography}

TEE was performed within 2 weeks of initial stroke or transient ischemic attack. TEE was a component of standard evaluation for patients in the study hospita $\left.\right|^{16}$ and was performed in all patients except for those with altered consciousness, progressing brain herniation, poor systemic condition, tracheal intubation, failure to introduce an esophageal transducer, or lack of informed consent. Detailed method of performing TEE was described in supplemental methods. ${ }^{19}$ Maximal thickness of plaques was used in this study. AAs were classified as CAP or simple aortic plaque (SAP). CAPs consisted of plaques protruding into the lumen by $\geq 4 \mathrm{~mm}$ and mobile lesions located in the proximal aorta. SAPs were plaques $<4 \mathrm{~mm}$ in the proximal aorta or plaques of any size located in the descending aorta. ${ }^{20}$ Patients who had both CAP and SAP were categorized into the CAP group because CAP is a more advanced form of AA and is regarded a potential cause of stroke. Two cardiologists who are experts in echocardiography interpreted the TEE results. In cases of discrepancy, the final decision was made by consensus., ${ }^{3,19}$

\section{Risk factors and definitions of variables}

The clinical variables including risk factors (hypertension, diabetes mellitus, hyperlipidemia, current smoking, coronary artery disease, the patient's prior medication and metabolic syndrome) were described as based on previous studies. The detail definition of clinical variables was elucidated in supplementary methods.

\section{MRI protocol and cerebral small vessel diseases}

All MRI examinations were performed on a 3.0T MRI machine (Achieva 3.0T; Philips Medical Systems, Best, Netherlands or MAGNETOM 3.0T Trio; Siemens, Germany). Parameters of diffusion-weighted imaging were time repetition/time echo $=2,600$ 6,500/42-70 ms, 2-mm inter-slice gap, field of view $=230 \times 230$ $\mathrm{mm}$, and slice thickness $=5 \mathrm{~mm}$. Two b-values $(0,1,000)$ in six different directions of diffusion gradient $(x, y, z, x y, y z, z x)$ were calculated. The fluid-attenuated inversion recovery image was performed with time repetition/time echo $=9,000 / 120 \mathrm{~ms}$, pixel spacing $=0.449 \mathrm{~mm} / 0.449 \mathrm{~mm}$, field of view $=230 \times 230 \mathrm{~mm}$, and slice thickness $=5 \mathrm{~mm}$. The gradient recalled echo images were obtained at time repetition/time echo $=600 / 16 \mathrm{~ms}$, pixel spacing $=0.449 \mathrm{~mm} / 0.449 \mathrm{~mm}$, field of view $=250 \times 250 \mathrm{~mm}$, and slice thickness $=5 \mathrm{~mm}$.

Cerebral SVDs, including CMBs, WMHs, PVSs, and ALIs, were defined according to MRI findings (Figure 1). All lesions of SVDs should not be located in acute infarctions on diffusion-weighted imaging (Supplementary Figure 1, 2). ${ }^{21}$ CMBs were indicated as punctate hypointense lesion less than $10 \mathrm{~mm}$ in size and located in brain parenchyma. ${ }^{22}$ For this study, CMBs were classified as strictly lobar or non-lobar. Strictly lobar CMBs were defined as CMBs located only in the lobar location, whereas non-lobar CMBs were found in the non-lobar location, with or without one 


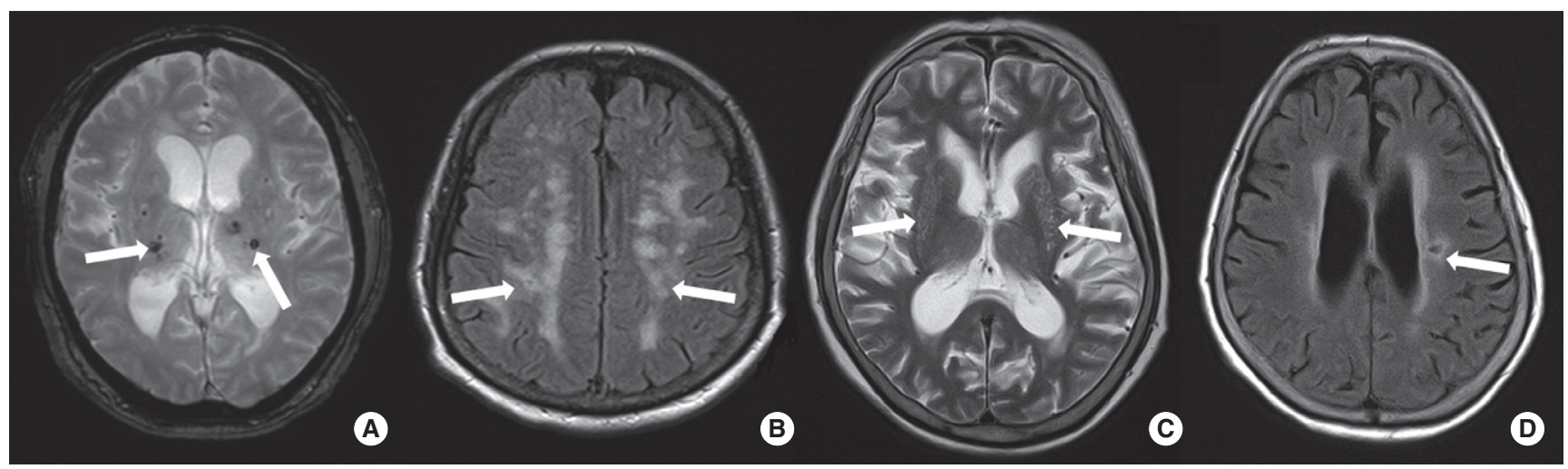

Figure 1. Illustrative imaging findings of cerebral small vessel diseases. (A) Cerebral microbleeds (arrows), (B) high-grade white matter hyperintesities (arrows), (C) high-grade perivascular spaces (arrows), and (D) asymptomatic lacunar infarction (arrows).

or more lobar CMBs. Strictly lobar CMBs were defined when a patient had possible or probable cerebral amyloid angiopathy (CAA), as defined previously. ${ }^{23}$ We also assessed the severity of WMHs. The extent of WMHs was determined on the fluid-attenuated inversion recovery images of periventricular white matter or deep white matter according to Fazekas' scoring system. ${ }^{24} \mathrm{~A}$ Fazekas score $\geq 2$ in periventricular white matter and/or $\geq 2$ in deep white matter was regarded as high-grade WMHs. PVSs were defined as punctate and/or linear hyperintense lesion in the basal ganglia on T2-weighted images. PVSs were $<3 \mathrm{~mm}$ in size and were classified with the following scale: grade 0 , no PVS; grade 1, 1-10 PVSs; grade 2, 11-20 PVSs; grade 3, 21-40 PVSs; and grade $4, \geq 40$ PVSs. High-grade PVSs were defined when lesions of grade 2-4 were found in the basal ganglia and centrum semiovale. ${ }^{25}$ Alls were defined when the patients had no history of symptoms or signs of previous stroke. The imaging criterion of ALls was one or more cavitary lesions with high-signal lesions on fluid-attenuated inversion recovery and T2-weighted images and low signal intensities on T1-weighted images. Size limitation of ALls was $\geq 3 \mathrm{~mm}$ and $<15 \mathrm{~mm} \cdot{ }^{26}$ According to a previous study, total SVD score was calculated by summation of 1 point for the presence of each of CMBs, high-grade WMHs, high-grade PVSs, or ALIs. The range of total SVD score was therefore $0-4 .{ }^{27}$ Two investigators who were blinded to the patient's clinical information independently assessed the presence of SVD lesions. Interobserver agreement (kappa values) for presence of $\mathrm{CMBs}$, high-grade WMHs, high-grade PVSs, and ALls was 0.92, 0.84, 0.88, and 0.82, respectively. If there was disagreement, a final decision was reached by consensus.

\section{Arterial stiffness}

Arterial stiffness was evaluated by brachial-ankle pulse wave velocity (baPWV). The baPWV was measured using an automated device (VP-1000; Colin Co. Ltd, Komaki, Japan) while the patients were in the supine position. After resting for 5 minutes, the pulse wave was simultaneously detected in the upper arms and ankles. Time difference between the upper arm and ankle waveforms was measured automatically.

\section{Statistical analysis}

Statistical analyses were performed using Windows SPSS package (version 20.0, Chicago, IL, USA). Continuous variables were reported as mean \pm SD and categorical variables as frequency and percentage. Chi-square test, Fisher exact test, and independent $t$ test were used for comparisons. To determine the association between $C M B s$ burden and $A A$, patients with $C M B s$ were categorized into three groups according to number of CMBs (none, 1-2, and $\geq 3$ ). ${ }^{26}$ Multivariable analysis was performed using the factors with a $P$ value $<0.1$ in the univariable analysis. Independent factors of presence of AAs were determined with binary logistic regression analysis. For the existence of CAP and SAP, multinomial logistic regression analysis was used with CAPs and SAPs as dependent variables. Because the variance inflation factor was higher than six among SVDs, each SVD and total SVD score were separately analyzed in multivariable analyses. Statistical significance was set at $P<0.05$. Odds ratios (OR) and 95\% confidence interval (Cl) were also calculated.

\section{Results}

\section{Study patients}

Among the 1,888 patients who were prospectively registered in the stroke data base, patients with transient ischemic attack $(n=177)$, stroke due to other rare causes $(n=45)$, and incomplete stroke evaluation $(n=18)$ were excluded. Patients without evaluation by TEE $(n=759)$, brain MRI $(n=81)$, gradient recalled echo images $(n=35)$, lack of vascular imaging studies $(n=32)$, or poor image quality $(n=4)$ were also excluded. Finally, a total of 
Table 1. Demographic characteristics of patients with aortic atheroma (AA)

\begin{tabular}{|c|c|c|c|c|c|c|c|}
\hline & $\begin{array}{c}\text { Total } \\
(n=737)\end{array}$ & $\begin{array}{c}\text { AAs (+) } \\
(n=360)\end{array}$ & $\begin{array}{c}\text { AAs (-) } \\
(n=377)\end{array}$ & $P$ value & $\begin{array}{c}\text { CAPs } \\
(n=86)\end{array}$ & $\begin{array}{c}\text { SAPs } \\
(n=274)\end{array}$ & $P$ value $^{*}$ \\
\hline Age (year) & $63 \pm 12$ & $66 \pm 9$ & $59 \pm 13$ & 0.001 & $69 \pm 8$ & $65 \pm 9$ & 0.001 \\
\hline Sex (male) & $461(62.6)$ & $245(68.1)$ & $216(57.3)$ & 0.003 & $68(79.1)$ & $177(64.6)$ & 0.012 \\
\hline \multicolumn{8}{|l|}{ Risk factors } \\
\hline Hypertension & $580(78.7)$ & $302(83.9)$ & $278(73.7)$ & 0.001 & $69(80.2)$ & $233(85.0)$ & 0.314 \\
\hline Diabetes Mellitus & $248(33.6)$ & $146(40.6)$ & $102(27.1)$ & 0.001 & $37(43.0)$ & 109 (39.8) & 0.593 \\
\hline Hyperlipidemia & $56(7.6)$ & $35(9.7)$ & $21(5.6)$ & 0.033 & $7(8.1)$ & $28(10.2)$ & 0.679 \\
\hline Smoking & $202(27.4)$ & $98(27.2)$ & $104(27.6)$ & 0.912 & $30(34.9)$ & $68(24.8)$ & 0.072 \\
\hline Atrial fibrillation & $125(17.0)$ & $62(17.2)$ & $63(16.7)$ & 0.853 & $14(16.3)$ & 48 (17.5) & 0.949 \\
\hline Metabolic syndrome & $284(38.5)$ & 158 (43.9) & $126(33.4)$ & 0.004 & $31(36.0)$ & $127(46.4)$ & 0.106 \\
\hline Previous stroke & 135 (18.3) & $74(20.6)$ & $61(16.2)$ & 0.125 & 14 (16.3) & $60(21.9)$ & 0.288 \\
\hline Coronary artery disease & $159(21.6)$ & $103(28.6)$ & $56(14.9)$ & 0.001 & $23(26.7)$ & $80(29.2)$ & 0.785 \\
\hline Congestive heart failure & $29(3.9)$ & $11(3.1)$ & $18(4.8)$ & 0.230 & $0(0.0)$ & $11(4.0)$ & 0.073 \\
\hline \multicolumn{8}{|l|}{ Previous medications } \\
\hline Anti-platelet & $199(27.0)$ & $104(28.9)$ & $95(25.2)$ & 0.259 & 32 (37.2) & $72(26.3)$ & 0.057 \\
\hline Anti-coagulant & $51(6.9)$ & $29(8.1)$ & $22(5.8)$ & 0.235 & $5(5.8)$ & $24(8.8)$ & 0.498 \\
\hline Lipid lowering agents & $94(12.8)$ & $49(13.6)$ & 45 (11.9) & 0.496 & $13(15.1)$ & $36(13.1)$ & 0.718 \\
\hline Stroke classification & & & & 0.001 & & & 0.001 \\
\hline Large artery atherosclerosis & $186(25.2)$ & $98(27.2)$ & $88(23.3)$ & & $37(43.0)$ & $61(22.3)$ & \\
\hline Lacunar infarction & $58(7.9)$ & $23(6.4)$ & $35(9.3)$ & & $0(0.0)$ & $23(8.4)$ & \\
\hline Cardioembolism & $174(23.6)$ & $70(19.4)$ & $104(27.6)$ & & $0(0.0)$ & $70(25.5)$ & \\
\hline Undetermined two or more causes identified & $154(20.9)$ & 98 (27.2) & $56(14.9)$ & & $49(57.0)$ & 49 (17.9) & \\
\hline Undetermined due to negative evaluation & $165(22.4)$ & $71(19.7)$ & $94(24.9)$ & & $0(0.0)$ & $71(25.9)$ & \\
\hline
\end{tabular}

Values are number $(\%)$ or means \pm standard deviation.

AAs, aortic atheromas; CAPs, complex aortic plaques; SAPs, simple aortic plaques.

*Comparison between SAPs and CAPs.

737 patients were included (Supplemental Figure 3). Patients who underwent TEE were younger $(P=0.001)$, more likely to be smokers $(P=0.021)$, and less frequently had a history of stroke $(P=0.010)$ than those without TEE, although the other variables were similar between the groups (Supplementary Table 1).

\section{Aortic atheroma and cerebral small vessel diseases}

AA was found by TEE in 360 (48.8\%) patients, including 11.6\% with CAP and $37.2 \%$ with SAP. Patients with AA were older and included a higher proportion of males compared to those without AA. Most risk factors, including hypertension, diabetes mellitus, hyperlipidemia, coronary artery disease, and metabolic syndrome were more common in patients with AA. In the TOAST classification, large artery atherosclerosis was similar between patients with AA and those without. Undetermined two or more causes identified were twice as common in patients with AA $(27.2 \%)$ as those without (14.9\%). The undetermined two or more causes identified subtypes were consisted of 59/98 (59.3\%) with large artery atherosclerosis plus lacunar infarction, 19/98 (19.4\%) with large artery atherosclerosis plus cardioembolism, 17/98 (17.3\%) with lacunar infarction plus cardioembolism, and $3 / 98$ (3.0\%) with large artery atherosclerosis plus lacunar infarction plus cardioembolism. Undetermined two or more causes identified subtype was more common in patients with CAP (57.0\%) than those with SAP (17.9\%) (Table 1). When we reclassified TOAST classification, patients with CAP more frequently had large artery atherosclerosis or lacunar infarction than those with SAP and without AA $(p=0.001)$ (Supplementary Table 2).

One or more types of SVDs were found in 269 (36.4\%) patients, including 161 (21.8\%) CMBs, 218 (29.6\%) high-grade WMHs, 152 (20.6\%) high-grade PVSs, and 230 (31.2\%) ALls. Among the patients with CMB, 153 (95.0\%) had non-lobar CMBs, and 8 (5.0\%) had strictly lobar CMBs, including 7 (4.3\%) with probable CAA and $1(0.7 \%)$ with possible CAA. Total SVD score $=0$ was found in $63.2 \%$ patients, 1 in 3.1\%, 2 in $11.7 \%, 3$ in $11.1 \%$, and 4 in $10.9 \%$. A total SVD score of 1 was found in 23 (3.1\%) patients, who most commonly had only CMB (52.1\%). In patients with a total SVD score of 2, the most common combination was high-grade WMH plus ALI in 86 patients (76.7\%). For patients with a total SVD score of 3, CMB plus high-grade PVS plus ALI was most common and was found in $82(40.2 \%)$ patients. Total SVD score was higher in patients with AA compared to those without and CAP compared to SAP (Table 2).

All subtypes of SVDs were common in patients with $A A$ and CAP (Table 2). Regarding the location of CMBs, strictly lobar and non-lobar CMBs were more common in patients with $A A$ than in 
Table 2. Univariable analysis for association between aortic atheroma (AA) and cerebral small vessel diseases (SVDs)

\begin{tabular}{|c|c|c|c|c|c|c|c|}
\hline & Total & $\begin{array}{c}\text { AAs }(+) \\
(n=360)\end{array}$ & $\begin{array}{c}\text { AAs (-) } \\
(n=377)\end{array}$ & $P$ value & $\begin{array}{c}\text { CAPs } \\
(n=86)\end{array}$ & $\begin{array}{c}\text { SAPs } \\
(n=274)\end{array}$ & $P$ value \\
\hline \multicolumn{8}{|l|}{ Cerebral Microbleeds (CMBs) } \\
\hline Presence & $161(21.8)$ & $128(35.6)$ & $33(8.8)$ & $<0.001$ & $43(50.0)$ & $85(31.0)$ & 0.002 \\
\hline Burden & & & & $<0.001$ & & & 0.002 \\
\hline CMBs 1-2 & $83(11.3)$ & $68(18.9)$ & $15(4.0)$ & & $26(30.2)$ & $42(15.3)$ & \\
\hline CMBs $\geq 3$ & $78(10.6)$ & $60(16.7)$ & $18(4.8)$ & & $17(19.8)$ & $43(15.7)$ & \\
\hline Distribution & & & & $<0.001$ & & & 0.001 \\
\hline Strictly lobar & $8(1.1)$ & $6(1.7)$ & $2(0.5)$ & & $4(4.7)$ & $2(0.7)$ & \\
\hline Non-lobar & $153(20.8)$ & $122(33.9)$ & $31(8.2)$ & & $39(45.3)$ & $83(30.3)$ & \\
\hline High-grade white matter hyperintensities (WMHs) & $218(29.6)$ & $158(43.9)$ & $60(15.9)$ & $<0.001$ & $49(57.0)$ & $109(39.8)$ & 0.006 \\
\hline Periventricular WMHs & $214(29.0)$ & $157(43.6)$ & $57(15.1)$ & $<0.001$ & $49(57.0)$ & $108(39.4)$ & 0.006 \\
\hline Deep WMHs & $176(23.9)$ & $130(36.1)$ & $46(12.2)$ & $<0.001$ & $43(50.0)$ & 87 (31.8) & 0.002 \\
\hline High-grade perivascular spaces & $152(20.6)$ & $115(31.9)$ & $37(9.8)$ & $<0.001$ & $40(46.5)$ & $75(27.4)$ & 0.001 \\
\hline Asymptomatic lacunar infarctions & $230(31.2)$ & $173(48.1)$ & $57(15.1)$ & $<0.001$ & $52(60.5)$ & $121(44.2)$ & 0.009 \\
\hline Total SVD score & & & & $<0.001$ & & & 0.001 \\
\hline 0 & $466(63.2)$ & $168(46.7)$ & $298(79.0)$ & & $28(32.6)$ & $140(51.1)$ & \\
\hline 1 & $23(3.1)$ & $8(2.2)$ & $15(4.0)$ & & $0(0.0)$ & $8(2.9)$ & \\
\hline 2 & $86(11.7)$ & $52(14.4)$ & $34(9.0)$ & & $17(19.8)$ & $35(12.8)$ & \\
\hline 3 & $82(11.1)$ & $66(18.3)$ & $16(4.2)$ & & $14(16.3)$ & $52(19.0)$ & \\
\hline 4 & $80(10.9)$ & 66 (18.3) & $14(3.7)$ & & $27(31.4)$ & $39(14.2)$ & \\
\hline
\end{tabular}

Values are number (\%) or means \pm SD.

AAs, aortic atheromas; CAPs, complex aortic plaques; SAPs, simple aortic plaques.

those without $(P<0.001)$. Patients with CAP had high-grade WMHs in both periventricular and deep white matter regions. Number of CMBs, degree of WMHs, and degree of PVSs were highest in patients with CAP, followed by those with SAP, compared to those without AA ( $P$ for trend $<0.001$ ). Moreover, CAP was more common as burden of total SVD score increased ( $P$ for trend $<0.001$ ) (Figure 2).

\section{Multivariable analysis of presence of AA}

Binary logistic regression analysis revealed that patients with AA were 4.68-fold (95\% $\mathrm{Cl} 3.01-7.28)$ more likely to have CMBs compared to those without. High-grade WMHs (OR 3.13, 95\% $\mathrm{Cl}$ 2.15-4.57), high-grade PVSs (OR 3.13, 95\% Cl 2.15-4.57), and presence of ALIs (OR 4.24, 95\% Cl 2.90-6.20) were also more common in patients with AA. Both periventricular and deep WMHs were common in patients with AA. Total SVD score $\geq 2$ was independently associated with presence of AA (Table 3).

In multinomial logistic regression analysis, patients with CAP (OR 8.72, 95\% Cl 4.71-16.14) or SAP (OR 3.94, 95\% Cl 2.486.25) more frequently had cerebral SVD. They also more commonly had all subtypes of SVDs. Regarding the location of CMBs, patients with CAP or SAP were more likely to have both non-lobar and strictly lobar CMBs. In particular, patients with CAP were more likely to have strictly lobar CMBs. Total SVD score $\geq 2$ was independently related with presence of CAP or SAP, and each 1-point increase in total SVD score increased the odds of presence of CAP (OR 1.94, 95\% Cl 1.44-1.85) and SAP (OR 1.54 95\%

\section{Cl 1.35-1.75) (Table 3).}

Sensitivity analysis of patients who underwent baPWV was conducted. Among total 737 patients, 143 patients who did not performe baPWV were excluded. Then, 174 patients who have potential cardiac sources of embolism were excluded because arrhythmia can prevent accurate measurement of baPWV and steno-occlusive lesions that can be indistinguishable from cardiac embolism. ${ }^{28}$ Finally, 420 patients were included in subgroup analysis for relationship between AA and arterial stiffness. Regarding arterial stiffness, increased pulse wave velocity was associated with presence of $A A$ and higher burden of AA (CAP) but not SAP (Supplementary Table 3).

When applying reclassification of the TOAST classification, index acute lacunar infarction was not related with presence of AA but there were trend of their association (OR 1.67, 95\% Cl 0.93-2.99). Whereas the index lacunar infarction was independently associated with CAP (OR 3.27, 95\% Cl 1.51-7.08) but not with SAP (OR 1.19, 95\% Cl 0.61-2.30) (Supplementary Table 4).

\section{Discussion}

We demonstrated that patients with AA not only frequently had coexisting SVDs, but also had a higher burden of coexisting SVDs as measured by total SVD score. Patients with AA had higher numbers of $\mathrm{CMBs}$, higher grade WMHs, and higher grade PVSs compared to those without AA. Among subtypes of AAs, patients with CAP, and to a lesser extent those with SAP, had a 


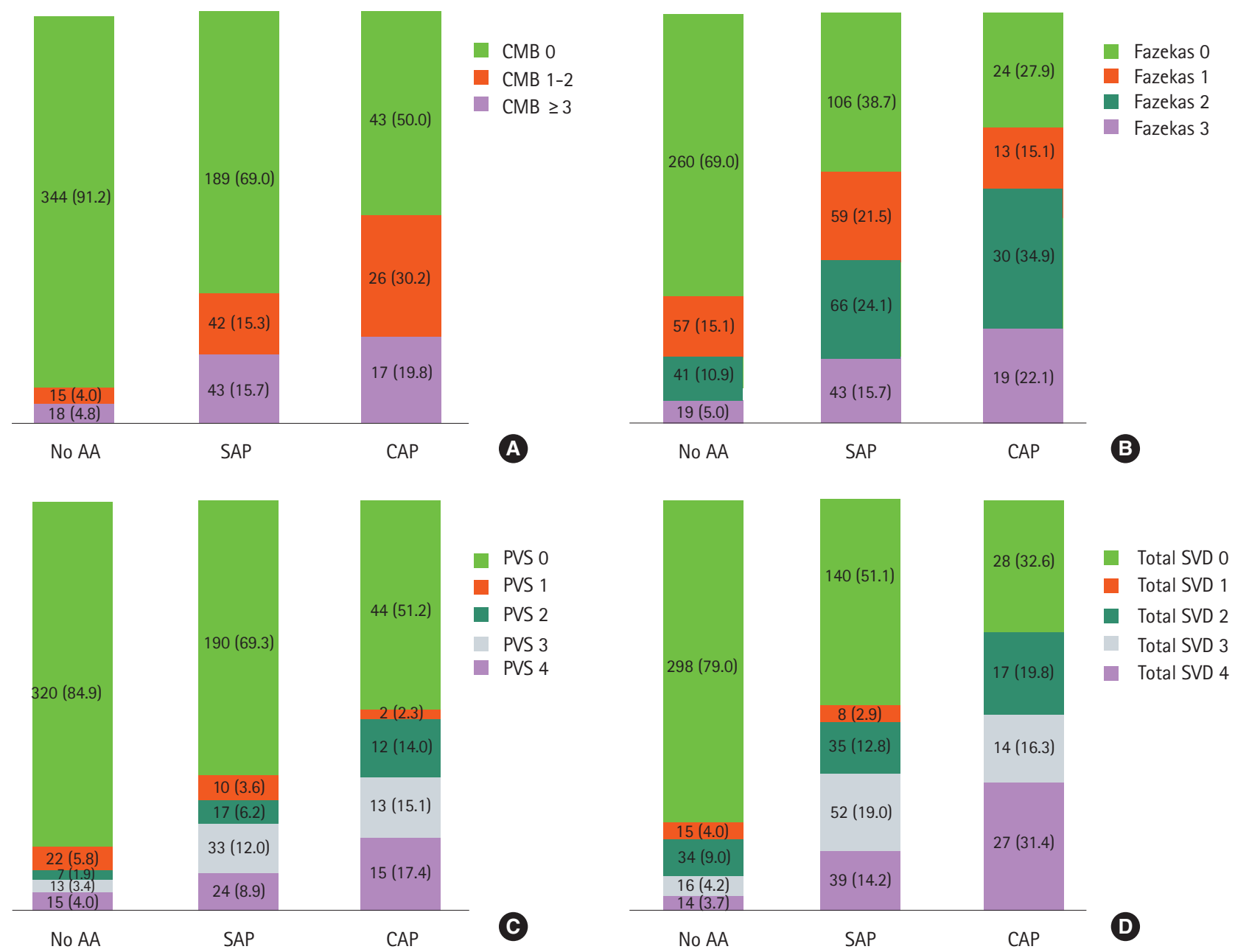

Figure 2. Association between aortic atheroma and burden of cerebral small vessel diseases. Number of CMBs (A), degree of high-grade WMH (B), degree of PVS (C), and total SVD score (D) were highest in patients with CAP, followed by those with SAP, compared to patients without AA ( $P$ for trend $<0.001)$. $A A$, aortic atheroma; $C M B$, cerebral microbleed; $S A P$, simple aortic plaque; $C A P$, complex aortic plaque; WMH, white matter hyperintensity; PVS, perivascular space; SVD, small vessel disease.

higher number of CMBs, a higher degree of WMHs, high-grade PVSs than those without AA.

Few studies have reported the association between AA and coexisting SVDs. As mentioned above, a case control study showed that presence of proximal AA was associated with lacunar infarction. ${ }^{14}$ An autopsy study demonstrated that ulcerated plaque in the aortic arch was frequent in patients with cryptogenic stroke. Nine of 17 patients with ulcerated plaque had lacunar infarction. ${ }^{4}$ Another study showed that AA evaluated by computed tomography angiography in patients with cryptogenic stroke was associated with SVDs. ${ }^{29}$ However, there is no study evaluating association between AA determined TEE and subtypes of SVDs and AA. In this study, index lacunar infarction was not associated with $A A$ and frequency of lacunar infarction on the TOAST classification in our study was low. These findings might be caused by our classifying methods with the TOAST classifica- tion. Using the TOAST classification, we considered CAPs as one of large artery atherosclerosis. Applying the reclassified TOAST classification when CAPs were not considered as one of large artery atherosclerosis, the index lacunar infarction was independently associated with CAP but not with SAP. These findings suggest that $A A$ are associated with both coexisting cerebral SVDs and index acute lacunar infarction.

Pathophysiologies of large artery atherosclerosis and SVDs in ischemic stroke are different. Plaque rupture and artery-to-artery embolism are major mechanisms in large artery atherosclerosis, whereas lipohyalinosis and parent artery atherosclerosis in $\mathrm{SVDs}^{30}$ It is uncertain whether AA is merely coexistent or mechanistically connected with SVDs. ${ }^{14}$ Exact mechanism for the association between burdens of AA and coexisting SVDs cannot be drawn from our study. Association between AA and SVDs in our study can be explained by the following hypotheses. First, in- 
Table 3. Multivariable analysis for association between aortic atheroma (AA) and cerebral small vessel diseases (SVDs)

\begin{tabular}{|c|c|c|c|c|c|c|}
\hline & \multicolumn{2}{|c|}{ Binary logistic regression* } & \multicolumn{4}{|c|}{ Multinomial multivariate logistic regression* } \\
\hline & $\begin{array}{c}\text { Adjusted OR } \\
(95 \% \mathrm{Cl}) \text { for AAs }\end{array}$ & $P$ value & $\begin{array}{c}\text { Adjusted OR } \\
(95 \% \mathrm{Cl}) \text { for CAPs }\end{array}$ & $P$ value & $\begin{array}{c}\text { Adjusted OR } \\
95 \% \mathrm{Cl} \text { ) for SAPs }\end{array}$ & $P$ value \\
\hline \multicolumn{7}{|l|}{ Cerebral microbleeds (CMBs) } \\
\hline Presence & $4.68(3.01-7.28)$ & 0.001 & $8.72(4.71-16.14)$ & 0.001 & $3.94(2.48-6.25)$ & 0.001 \\
\hline \multicolumn{7}{|l|}{ Burden } \\
\hline CMBs 1-2 & $5.54(3.01-10.19)$ & 0.001 & $12.46(5.69-27.25)$ & 0.026 & $4.38(2.32-8.30)$ & 0.013 \\
\hline $\mathrm{CMBs} \geq 3$ & $3.95(2.19-7.11)$ & 0.022 & $5.70(2.49-13.03)$ & 0.041 & $3.56(1.94-6.53)$ & 0.042 \\
\hline \multicolumn{7}{|l|}{ Distribution } \\
\hline Non-lobar & $4.61(2.93-7.25)$ & 0.017 & $7.88(4.19-14.82)$ & 0.037 & $3.99(2.49-6.38)$ & 0.004 \\
\hline Strictly lobar & $5.89(1.07-33.24)$ & 0.001 & $43.32(5.36-349.54)$ & 0.016 & $2.60(0.34-19.77)$ & 0.714 \\
\hline High-grade white matter hyperintensities (WMHs) & $3.13(2.15-4.57)$ & 0.035 & $5.27(2.96-9.37)$ & 0.025 & $2.73(1.84-4.05)$ & 0.017 \\
\hline Periventricular WMHs & $3.31(2.26-4.86)$ & 0.031 & $5.35(2.43-11.76)$ & 0.021 & $2.87(1.93-4.28)$ & 0.012 \\
\hline Deep WMHs & $3.01(2.00-4.53)$ & 0.032 & $5.64(3.08-10.35)$ & 0.011 & $2.56(1.67-3.92)$ & 0.015 \\
\hline High-grade perivascular spaces & $3.35(2.17-5.17)$ & 0.038 & $5.70(3.19-10.19)$ & 0.035 & $2.74(1.75-4.31)$ & 0.021 \\
\hline Asymptomatic lacunar infarctions & $4.24(2.90-6.20)$ & 0.003 & $6.92(3.88-12.34)$ & 0.041 & $3.74(2.51-5.56)$ & 0.005 \\
\hline \multicolumn{7}{|l|}{ Total SVD score } \\
\hline 0 & Reference & & Reference & & Reference & \\
\hline 1 & $0.74(0.30-1.83)$ & 0.521 & No cases & & $0.76(0.29-1.97)$ & 0.580 \\
\hline 2 & $2.07(1.24-3.44)$ & 0.035 & $4.76(2.01-11.28)$ & 0.026 & $1.75(1.03-3.03)$ & 0.043 \\
\hline 3 & $6.46(3.49-1.94)$ & 0.038 & 10.38 (3.94-27.35) & 0.041 & $5.91(3.17-11.02)$ & 0.032 \\
\hline 4 & $6.10(3.21-11.62)$ & 0.003 & $18.27(7.07-47.18)$ & 0.002 & $4.71(2.40-9.25)$ & 0.002 \\
\hline Total SVD score (per 1 point) & $1.63(1.44-1.85)$ & 0.001 & $1.94(1.62-2.32)$ & 0.001 & $1.54(1.35-1.75)$ & 0.001 \\
\hline
\end{tabular}

$\mathrm{OR}$, Odds ratio; $\mathrm{Cl}$, confidence interval; $\mathrm{AAs}$, aortic atheromas; CAPs, complex aortic plaques; $\mathrm{SAPs}$, simple aortic plaques.

*No AAs as references. Adjusted by age, sex, hypertension, diabetes mellitus, hyperlipidemia, coronary artery disease, the prior antiplatelet medication, and stroke subtypes.

creased arterial stiffness which related with progressed AA may explain the results of our study. In previous studies, increased arterial stiffness was positively associated with larger burden of AA. ${ }^{31,32}$ Arterial stiffness increases the pulse pressure and contributes to systemic hypertensive injury. ${ }^{11}$ Previous studies showed that the presence of cerebral SVDs was correlated with increased augmentation index and pulse wave velocity which representing arterial stiffness. ${ }^{28,31,32}$ Because brain vessels have a low vascular resistance, SVDs are vulnerable to increased pulse pressure." In addition, increased arterial stiffness on CAP comparing with that of SAP in our study may be one of explanation of association with larger burden of AA and progressed SVDs. Second, large artery atherosclerosis and SVDs share common risk factors of ischemic stroke. Old age and chronic hypertension are associated with both AA and SVDs. ${ }^{33,34}$ Our study findings are in line with these previous studies. Although the TOAST subtype of large artery atherosclerosis was similar between patients with $\mathrm{AA}$ and those without, undetermined two or more causes (mainly large artery atherosclerosis and lacunar infarction) were twice as common in patients with AA. These findings suggest development of stroke in patients with AAs may not be solely dependent on large artery atherosclerosis. Third, inflammatory processes play a key role in the development of both AA and SVDs. Patients with $A A$ had a higher leukocyte count and higher levels of in- flammatory cytokines. ${ }^{35}$ Similarly, patients with SVDs had higher levels of inflammatory markers. ${ }^{36}$ Lastly, SVDs can be derived from emboli itself caused by AA. A clinical study showed that microembolic signals in transcranial Doppler were frequent in patients with $A A^{37}$ Autopsy or clinical studies suggested that thrombotic or cholesterol emboli from ulcerated plaque in $A A$ may cause SVDs. ${ }^{38}$

Our study showed that AA was closely related to CMBs. In particular, we firstly demonstrated that strictly lobar CMBs was associated with CAP but not with SAP, whereas non-lobar CMBs was frequent in both CAP and SAP. Pathophysiology of CMBs is known to be different according to location. Non-lobar CMBs is regarded as hypertensive vasculopathy, whereas lobar CMBs is associated with CAA. Relationship between non-lobar CMBs and AA could be explained by their sharing classic vascular risk factors, including hypertension and high pulse pressure, or increased arterial stiffness. ${ }^{11,32}$ In contrast, the patients with strictly lobar $\mathrm{CMBs}$ may have risk factors of CAA. ${ }^{39}$ Because, exact mechanism for association between CAPs and strictly lobar CMBs cannot be identified in our study, further research is mandatory to solve it.

Our study also firstly demonstrated the association between PVSs and AA. A previous study showed that patients with PVSs were more likely to exhibit vascular dementia as opposed to Alzheimer disease. ${ }^{40}$ PVS was closely related with $\mathrm{WMHs}_{1}{ }^{41}$ in- 
creased blood-brain barrier permeability, ${ }_{1}^{42}$ and inflammatory reaction. ${ }^{43}$ However, our results showed that grade of PVSs was associated with burden of $A A$, the reasons for this association remains uncertain.

We firstly demonstrated that association between total SVD score and burden of AAs. Each component of SVD shares risk factors and mechanisms of developing stroke. In clinical application, it is reasonable to consider various SVD with single representative score. Total SVD score was used to evaluate overall effect of SVD on the brain, rather than estimating the effects of 1 or 2 individual SVDs. ${ }^{27}$ Total SVD score was helpful for the rapid quantification or stratification of SVDs. Accordingly, our study gives new information about correlation in burdens of total SVD score and AA.

Our study has limitations. First, although this study was performed in the consecutive ischemic stroke patients who underwent TEE, the possibility of selection bias exists due to the retrospective nature of the analysis. In our hospital, TEE was routine stroke evaluation based on the previous reports of usefulness of TEE in evaluation of potential cardiac or aortic source of embolism. ${ }^{19,44}$ However, as routine evaluation of TEE may not be a common practice in other hospitals, it might be difficult to confirm our findings in those hospitals. Nonetheless, this is the largest study that evaluated the association between TEE evaluated $A A$ and SVDs. Second, strictly lobar CMBs were not confirmed by pathological study with presence of CAA. However, other studies were also conducted without pathologic confirmation. ${ }^{23}$ Third, small sample size of patients who had strictly lobar CMBs may result in statistical bias. Thus, the relationship between strictly lobar CMBs and CAP cannot be concluded. Therefore, caution must be needed when interpreting our results and further studies are required to identify our results.

\section{Conclusions}

In this study, patients with AA frequently had coexisting cerebral SVDs. We also demonstrated that larger burden of AA was associated with coexisting advanced cerebral SVDs. Our findings give an additional information for positive relationship with systemic atherosclerosis and coexisting cerebral SVDs in acute ischemic stroke patients.

\section{References}

1. Amarenco $P$, Cohen $A$, Tzourio $C$, Bertrand $B$, Hommel M, Besson $G$, et al. Atherosclerotic disease of the aortic arch and the risk of ischemic stroke. N Engl J Med 1994;331:1474-1479.

2. Ferrari $E$, Vidal $R$, Chevallier T, Baudouy M. Atherosclerosis of the thoracic aorta and aortic debris as a marker of poor prognosis: benefit of oral anticoagulants. J Am Coll Cardiol 1999; 33:1317-1322.

3. Amarenco $P$, Duyckaerts $C$, Tzourio $C$, Hénin $D$, Bousser MG, Hauw JJ. The prevalence of ulcerated plaques in the aortic arch in patients with stroke. N Engl J Med 1992;326:221-225.

4. Nam HS, Han SW, Lee JY, Ahn SH, Ha JW, Rim SJ, et al. Association of aortic plaque with intracranial atherosclerosis in patients with stroke. Neurology 2006;67:1184-1188.

5. Choi HY, Yang JH, Cho HJ, Kim YD, Nam HS, Heo JH. Systemic atherosclerosis in patients with perforating artery territorial infarction. Eur J Neurol 2010;17:788-793.

6. Tsai CF, Thomas B, Sudlow CL. Epidemiology of stroke and its subtypes in Chinese vs white populations: a systematic review. Neurology 2013;81:264-272.

7. Qureshi Al, Mendelow AD, Hanley DF. Intracerebral haemorrhage. Lancet 2009;373:1632-1644.

8. Kim BJ, Lee SH. Prognostic impact of cerebral small vessel disease on stroke outcome. J Stroke 2015;17:101-110.

9. Chuang ML, Gona P, Oyama-Manabe N, Manders ES, Salton $\mathrm{CJ}$, Hoffmann U, et al. Risk factor differences in calcified and noncalcified aortic plaque: the Framingham Heart Study. Arterioscler Thromb Vasc Biol 2014;34:1580-1586.

10. Pantoni L. Cerebral small vessel disease: from pathogenesis and clinical characteristics to therapeutic challenges. Lancet Neurol 2010;9:689-701.

11. O'Rourke MF, Safar ME. Relationship between aortic stiffening and microvascular disease in brain and kidney: cause and logic of therapy. Hypertension 2005;46:200-204.

12. Kong $\mathrm{Q}, \mathrm{Ma} \mathrm{X}$. Contributing mechanisms of aortic atheroma in ischemic cerebrovascular disease. J Stroke Cerebrovasc Dis 2015;24:2653-2659.

13. Kandiah N, Goh O, Mak E, Marmin M, Ng A. Carotid stenosis: a risk factor for cerebral white-matter disease. J Stroke Cerebrovasc Dis 2014;23:136-139.

14. Kazui $S$, Levi $C R$, Jones $E F$, Quang $L$, Calafiore $P$, Donnan $G A$. Risk factors for lacunar stroke: a case-control transesophageal echocardiographic study. Neurology 2000;54:1385-1387.

15. Lee BI, Nam HS, Heo JH, Kim DI; Yonsei Stroke Team. Yonsei Stroke Registry. Analysis of 1,000 patients with acute cerebral infarctions. Cerebrovasc Dis 2001;12:145-151.

16. Nam HS, Kim HC, Kim YD, Lee HS, Kim J, Lee DH, et al. Longterm mortality in patients with stroke of undetermined etiology. Stroke 2012;43:2948-2956.

17. Adams HP Jr, Bendixen BH, Kappelle ப, Biller J, Love BB, Gordon $\mathrm{DL}$, et al. Classification of subtype of acute ischemic stroke. Definitions for use in a multicenter clinical trial. TOAST. Trial of Org 10172 in Acute Stroke Treatment. Stroke 1993;24:35-41. 
18. Oh MS, Yu KH, Lee JH, Jung S, Ko IS, Shin JH, et al. Validity and reliability of a Korean version of the national institutes of health stroke scale. J Clin Neurol 2012;8:177-183.

19. Cho HJ, Choi HY, Kim YD, Nam HS, Han SW, Ha JW, et al. Transoesophageal echocardiography in patients with acute stroke with sinus rhythm and no cardiac disease history. J Neurol Neurosurg Psychiatry 2010;81:412-415.

20. Demopoulos LA, Tunick PA, Bernstein NE, Perez JL, Kronzon I. Protruding atheromas of the aortic arch in symptomatic patients with carotid artery disease. Am Heart J 1995;129:40-44.

21. Song TJ, Chang Y, Shin MJ, Heo JH, Kim YJ. Low levels of plasma omega 3-polyunsaturated fatty acids are associated with cerebral small vessel diseases in acute ischemic stroke patients. Nutr Res 2015;35:368-374.

22. Wardlaw JM, Smith EE, Biessels GJ, Cordonnier C, Fazekas F, Frayne $R$, et al. Neuroimaging standards for research into small vessel disease and its contribution to ageing and neurodegeneration. Lancet Neurol 2013;12:822-838.

23. Greenberg SM. Cerebral amyloid angiopathy: prospects for clinical diagnosis and treatment. Neurology 1998;51:690-694.

24. Fazekas F, Chawluk JB, Alavi A, Hurtig HI, Zimmerman RA. MR signal abnormalities at $1.5 \mathrm{~T}$ in Alzheimer's dementia and normal aging. AJR Am J Roentgenol 1987;149:351-356.

25. Doubal FN, MacLullich AM, Ferguson KJ, Dennis MS, Wardlaw JM. Enlarged perivascular spaces on MRI are a feature of cerebral small vessel disease. Stroke 2010;41:450-454.

26. Song TJ, Kim J, Song D, Nam HS, Kim YD, Lee HS, et al. Association of cerebral microbleeds with mortality in stroke patients having atrial fibrillation. Neurology 2014;83:1308-1315.

27. Staals J, Makin SD, Doubal FN, Dennis MS, Wardlaw JM. Stroke subtype, vascular risk factors, and total MRI brain small-vessel disease burden. Neurology 2014;83:1228-1234.

28. Song TJ, Kim J, Kim YD, Nam HS, Lee HS, Nam CM, et al. The distribution of cerebral microbleeds determines their association with arterial stiffness in non-cardioembolic acute stroke patients. Eur J Neuro/ 2014;21:463-469.

29. Chatzikonstantinou A, Krissak R, Schaefer A, Schoenberg SO, Fink $C$, Hennerici MG. Coexisting large and small vessel disease in patients with ischemic stroke of undetermined cause. Eur Neurol 2012;68:162-165.

30. Caplan LR. Lacunar infarction and small vessel disease: pathology and pathophysiology. J Stroke 2015;17:2-6.

31. Szmigielski C, Styczyński G, Sobczyńska M, Milewska A, Placha $G$, Kuch-Wocial A. Pulse wave velocity correlates with aortic atherosclerosis assessed with transesophageal echocardiography. J Hum Hypertens 2016;30:90-94.

32. Nakano T, Munakata A, Shimaura N, Asano K, Ohkuma H. Augmentation index is related to white matter lesions. Hypertens
Res 2012;35:729-732.

33. Greenberg SM, Vernooij MW, Cordonnier C, Viswanathan $A$, Al-Shahi Salman R, Warach $S$, et al. Cerebral microbleeds: a guide to detection and interpretation. Lancet Neurol 2009;8: 165-174.

34. Aboyans V, Lacroix P, Criqui MH. Large and small vessels atherosclerosis: similarities and differences. Prog Cardiovasc Dis 2007;50:112-125.

35. Elkind MS, Sciacca R, Boden-Albala B, Homma S, Di Tullio MR. Leukocyte count is associated with aortic arch plaque thickness. Stroke 2002;33:2587-2592.

36. Umemura $T$, Kawamura $T$, Umegaki $H$, Mashita $S$, Kanai $A$, Sakakibara $T$, et al. Endothelial and inflammatory markers in relation to progression of ischaemic cerebral small-vessel disease and cognitive impairment: a 6-year longitudinal study in patients with type 2 diabetes mellitus. J Neurol Neurosurg Psychiatry 2011;82:1186-1194.

37. Rundek T, Di Tullio MR, Sciacca RR, Titova IV, Mohr JP, Homma $S$, et al. Association between large aortic arch atheromas and high-intensity transient signals in elderly stroke patients. Stroke 1999;30:2683-2686.

38. Altaf N, Daniels L, Morgan PS, Lowe J, Gladman J, MacSweeney ST, et al. Cerebral white matter hyperintense lesions are associated with unstable carotid plaques. Eur J Vasc Endovasc Surg 2006;31:8-13.

39. Vernooij MW, van der Lugt A, Ikram MA, Wielopolski PA, Niessen WJ, Hofman $A$, et al. Prevalence and risk factors of cerebral microbleeds: the Rotterdam Scan Study. Neurology 2008; 70:1208-1214.

40. Patankar TF, Mitra D, Varma A, Snowden J, Neary D, Jackson A. Dilatation of the Virchow-Robin space is a sensitive indicator of cerebral microvascular disease: study in elderly patients with dementia. AJNR Am J Neuroradiol 2005;26:1512-1520.

41. Rouhl RP, van Oostenbrugge RJ, Knottnerus IL, Staals JE, Lodder J. Virchow-Robin spaces relate to cerebral small vessel disease severity. J Neuro/ 2008;255:692-696.

42. Starr JM, Wardlaw J, Ferguson K, MacLullich A, Deary IJ, Marshall I. Increased blood-brain barrier permeability in type II diabetes demonstrated by gadolinium magnetic resonance imaging. J Neurol Neurosurg Psychiatry 2003;74:70-76.

43. Wuerfel J, Haertle M, Waiczies $H_{1}$ Tysiak E, Bechmann I, Wernecke $K D$, et al. Perivascular spaces-MRI marker of inflammatory activity in the brain? Brain 2008;131:2332-2340.

44. Comess KA, DeRook FA, Beach KW, Lytle NJ, Golby AJ, Albers GW. Transesophageal echocardiography and carotid ultrasound in patients with cerebral ischemia: prevalence of findings and recurrent stroke risk. J Am Coll Cardiol 1994;23:15981603. 


\section{Supplementary methods}

\section{Transesophageal echocardiography (TEE)}

Patients undergoing TEE fasted and received local pharyngeal anesthesia with 10\% topical lidocaine prior to the examination. A commercially available TEE machine (iE33 xMATRIX, Philips) equipped with a multiplane $5-\mathrm{MHz}$ transducer was used for the assessment of aortic atherosclerosis. TEE images were obtained using transgastric, midesophageal, and basal views. All segments of the thoracic aorta, including the ascending aorta, the aortic arch, and the descending aorta, were evaluated between 0 and 90 degrees. AA was defined as a discrete protrusion of the intimal surface of the aorta with different morphology and echogenicity. Plaque thickness was recorded as the whole thickness of the intima and media in the aortic wall and was measured perpendicularly in a frozen frame during systole. ${ }^{\prime}$

\section{Risk factors and definitions of variables}

Hypertension was diagnosed when a patient showed resting systolic blood pressure $\geq 140 \mathrm{mmHg}$ or diastolic blood pressure $\geq 90 \mathrm{mmHg}$ in repeated measurements or was being treated with antihypertensive medication. Diabetes mellitus was diagnosed when a patient showed fasting blood glucose $\geq 7.0 \mathrm{mmol} /$ $\mathrm{L}$ or was being treated with antidiabetic medications. Hyperlipidemia was diagnosed when a patient had low-density lipoprotein cholesterol $\geq 4.1 \mathrm{mmol} / \mathrm{L}$ or total cholesterol $\geq 6.2 \mathrm{mmol} / \mathrm{L}$. Smokers were defined as current smokers or individuals who had stopped smoking within one year before the current ischemic stroke. Presence of coronary artery disease was determined when a patient had a history of unstable angina, coronary artery occlusive disease, or myocardial infarction. Metabolic syndrome was diagnosed when a patient had more than three components of abdominal obesity (waist circumference $>102 \mathrm{~cm}$ for men, $>88 \mathrm{~cm}$ for women); triglycerides $\geq 1.7 \mathrm{mmol} / \mathrm{L}$; low level of high-density lipoprotein $(<1.04 \mathrm{mmol} / \mathrm{L}$ for men, $<1.30 \mathrm{mmol} / \mathrm{L}$ for women); or blood pressure greater than $130 / 85 \mathrm{mmHg}$; or fasting glucose $\geq 6.1 \mathrm{mmol} / \mathrm{L}^{2,3}$

\section{References}

1. Cho HJ, Choi HY, Kim YD, Nam HS, Han SW, Ha JW, et al. Transoesophageal echocardiography in patients with acute stroke with sinus rhythm and no cardiac disease history. J Neurol Neurosurg Psychiatry 2010;81:412-415.

2. National Cholesterol Education Program (NCEP) Expert Panel on Detection, Evaluation, and Treatment of High Blood Cholesterol in Adults (Adult Treatment Panel III). Third Report of the National Cholesterol Education Program (NCEP) Expert Panel on Detection, Evaluation, and Treatment of High Blood Cholesterol in Adults (Adult Treatment Panel III) final report. CCirculation 2002;106:3143-3421.

3. Song TJ, Kim J, Song D, Nam HS, Kim YD, Lee HS, et al. Association of cerebral microbleeds with mortality in stroke patients having atrial fibrillation. Neurology 2014;83:1308-1315. 
Supplementary Table 1. Comparison between performed transesophageal echocardiography (TEE) or not performed

\begin{tabular}{lccc}
\hline & TEE $(+)(n=737)$ & TEE $(-)(n=759)$ & $P$ value \\
\hline $\begin{array}{l}\text { Demographic data } \\
\text { Sex (male) }\end{array}$ & $461(62.6)$ & $452(59.6)$ & 0.234 \\
Age, years \pm standard deviation (SD) & $63 \pm 12$ & $67 \pm 12$ & 0.001 \\
Risk factors & & & 0.113 \\
Hypertension & $580(78.7)$ & $622(81.9)$ & 0.897 \\
Diabetes Mellitus & $248(33.6)$ & $253(33.3)$ & 0.333 \\
Hyperlipidemia & $56(7.6)$ & $48(6.3)$ & 0.021 \\
Smoking & $202(27.4)$ & $169(22.3)$ & 0.960 \\
Atrial fibrillation & $125(17.0)$ & $128(16.8)$ & 0.010 \\
Previous stroke & $135(18.3)$ & $180(23.7)$ & 0.321 \\
Coronary artery disease & $159(21.6)$ & $148(19.5)$ & 0.179 \\
Congestive heart failure & $29(3.9)$ & $41(5.4)$ & 0.980 \\
Metabolic syndrome & $284(38.5)$ & $292(38.5)$ & 0.606 \\
Previous medications & & & 0.659 \\
Anti-platelet & $199(27.0)$ & $214(28.2)$ & 0.988 \\
Anti-coagulant & $51(6.9)$ & $57(7.5)$ & $97(12.8)$ \\
Lipid lowing agents & $94(12.8)$ & & \\
\hline
\end{tabular}

Values are number $(\%)$ or means \pm SD. 
Supplementary Table 2. The frequency of stroke classification according to presence and burden of aortic atheromas (AAs) based on reclassified trial of ORG 10172 in acute stroke treatment (TOAST) classification*

\begin{tabular}{|c|c|c|c|c|c|c|c|}
\hline & $\begin{array}{c}\text { AAs (-) } \\
(n=377)\end{array}$ & $\begin{array}{c}\text { AA (+) } \\
(n=360)\end{array}$ & $P$ value & $\begin{array}{c}\text { AAs (-) } \\
(n=377)\end{array}$ & $\begin{array}{c}\text { CAPs } \\
(n=86)\end{array}$ & $\begin{array}{c}\text { SAPs } \\
(n=274)\end{array}$ & $P$ value \\
\hline Reclassified TOAST classification & & & 0.432 & & & & 0.001 \\
\hline Large artery atherosclerosis & $88(23.3)$ & $86(23.9)$ & & $88(23.3)$ & $25(29.1)$ & $61(22.3)$ & \\
\hline Lacunar infarction & $35(9.3)$ & $47(13.1)$ & & $35(9.3)$ & $24(27.9)$ & $23(8.4)$ & \\
\hline Cardioembolism & $104(27.6)$ & $86(23.9)$ & & $104(27.6)$ & $16(18.6)$ & $70(25.5)$ & \\
\hline Undetermined two or more causes identified & $56(14.9)$ & $58(16.1)$ & & $56(14.9)$ & $9(10.5)$ & 49 (17.9) & \\
\hline Undetermined due to negative evaluation & $94(24.9)$ & $83(23.1)$ & & $94(24.9)$ & $12(14.0)$ & $71(25.9)$ & \\
\hline
\end{tabular}

Values are number (\%).

$\mathrm{OR}$, odds ratio; $\mathrm{Cl}$, confidence interval; $\mathrm{AAs}$, aortic atheromas; CAPs, complex aortic plaques; $\mathrm{SAPs}$, simple aortic plaques.

${ }^{*} \mathrm{CAP}$ was not considered as large artery atherosclerosis component on TOAST classification. 
Supplementary Table 3. Multivariable analysis for determining presence of aortic atheroma (AA) after adjusting brachial ankle pulse wave velocity

\begin{tabular}{|c|c|c|c|c|c|c|}
\hline & \multicolumn{2}{|c|}{$\begin{array}{c}\text { Binary logistic regression* } \\
\text { OR }(95 \% \mathrm{Cl})\end{array}$} & \multicolumn{4}{|c|}{$\begin{array}{l}\text { Multinomial multivariate logistic regression* } \\
\text { OR }(95 \% \mathrm{Cl})\end{array}$} \\
\hline & AAs $(n=210)$ & $P$ value & CAPs $(n=52)$ & $P$ value & SAPs $(n=158)$ & $P$ value \\
\hline Age & $1.06(1.04-1.09)$ & 0.001 & $1.11(1.06-1.16)$ & 0.001 & $1.05(1.02-1.08)$ & 0.001 \\
\hline Sex (male) & $2.07(1.29-3.32)$ & 0.002 & $3.54(2.73-6.48)$ & 0.002 & $1.70(1.23-2.62)$ & 0.001 \\
\hline Hypertension & $1.07(0.58-1.98)$ & 0.820 & $2.39(0.94-6.07)$ & 0.067 & $1.18(0.72-1.89)$ & 0.522 \\
\hline Diabetes Mellitus & $1.61(0.97-2.65)$ & 0.062 & $1.82(0.84-3.94)$ & 0.125 & $1.37(0.96-1.78)$ & 0.058 \\
\hline Hyperlipidemia & $1.73(0.78-3.86)$ & 0.174 & $1.73(0.57-4.34)$ & 0.220 & $1.69(0.95-3.63)$ & 0.075 \\
\hline Coronary artery disease & $2.28(1.33-3.92)$ & 0.003 & $1.28(0.55-2.96)$ & 0.556 & $1.82(1.37-2.84)$ & 0.005 \\
\hline Metabolic syndrome & $1.13(0.67-1.90)$ & 0.627 & $1.24(0.65-1.68)$ & 0.483 & $1.32(0.84-1.98)$ & 0.214 \\
\hline Previous anti-platelet & & & $1.98(1.04-3.65)$ & 0.038 & $0.91(0.62-1.43)$ & 0.426 \\
\hline \multicolumn{7}{|l|}{ Stroke classification } \\
\hline Large artery atherosclerosis & Reference & & Reference & & Reference & \\
\hline Lacunar infarction & $1.12(0.59-2.57)$ & 0.502 & No cases & & $1.01(0.53-1.93)$ & 0.455 \\
\hline $\begin{array}{l}\text { Undetermined due to two or } \\
\text { more causes identified }\end{array}$ & $0.78(0.53-1.21)$ & 0.125 & $1.67(0.92-2.38)$ & 0.082 & $0.82(0.38-1.78)$ & 0.625 \\
\hline $\begin{array}{l}\text { Undetermined due to negative } \\
\text { evaluation }\end{array}$ & $1.21(0.75-1.97)$ & 0.184 & No cases & & $1.07(0.72-1.84)$ & 0.826 \\
\hline Pulse wave velocity $(\mathrm{m} / \mathrm{s})$ & $1.02(1.00-1.04)$ & 0.047 & $1.03(1.01-1.05)$ & 0.037 & $1.01(0.97-1.01)$ & 0.223 \\
\hline
\end{tabular}

Number of patients for subgroup analysis: 420 .

$\mathrm{OR}$, odds ratio; $\mathrm{Cl}$, confidence interval; $\mathrm{AAs}$, aortic atheromas; CAPs, complex aortic plaques; SAPs, simple aortic plaques.

*No AAs as reference. 
Supplementary Table 4. Multivariable analysis for determining presence of aortic atheroma (AA) after adjusting reclassified trial of ORG 10172 in acute stroke treatment (TOAST) classification*

\begin{tabular}{|c|c|c|c|c|c|c|}
\hline & \multicolumn{2}{|c|}{$\begin{array}{l}\text { Binary logistic regression }{ }^{+} \\
\text {OR }(95 \% \mathrm{Cl})\end{array}$} & \multicolumn{4}{|c|}{$\begin{array}{l}\text { Multinomial multivariate logistic regression }{ }^{+} \\
\text {OR }(95 \% \mathrm{Cl})\end{array}$} \\
\hline & AAs & $P$ value & CAPs & $P$ value & SAPs & $P$ value \\
\hline Age & $1.06(1.04-1.07)$ & 0.001 & $1.11(1.07-1.14)$ & 0.001 & $1.04(1.03-1.06)$ & 0.001 \\
\hline Sex (male) & $2.09(1.49-2.92)$ & 0.001 & $4.23(2.30-7.78)$ & 0.001 & $1.73(1.21-2.45)$ & 0.002 \\
\hline Hypertension & $1.10(0.72-1.69)$ & 0.647 & $0.78(0.39-1.57)$ & 0.494 & $1.22(0.77-1.94)$ & 0.379 \\
\hline Diabetes Mellitus & $1.55(1.08-2.22)$ & 0.017 & $1.96(1.10-3.49)$ & 0.022 & $1.45(0.99-2.13)$ & 0.052 \\
\hline Hyperlipidemia & $1.82(0.99-3.36)$ & 0.053 & $2.14(0.80-5.72)$ & 0.127 & $1.77(0.94-3.33)$ & 0.073 \\
\hline Coronary artery disease & $1.73(1.17-2.56)$ & 0.005 & $1.35(0.73-2.50)$ & 0.331 & $1.84(1.24-2.76)$ & 0.003 \\
\hline Metabolic syndrome & $1.17(0.81-1.70)$ & 0.398 & $0.80(0.43-1.50)$ & 0.502 & $1.27(0.86-1.88)$ & 0.214 \\
\hline Previous anti-platelet & & & $2.14(1.05-4.08)$ & 0.037 & $0.93(0.65-1.46)$ & 0.538 \\
\hline \multicolumn{7}{|l|}{ Stroke classification } \\
\hline Large artery atherosclerosis & Reference & & Reference & & Reference & \\
\hline Lacunar infarction & $1.67(0.93-2.99)$ & 0.081 & $3.27(1.51-7.08)$ & 0.003 & $1.19(0.61-2.30)$ & 0.602 \\
\hline Cardioembolism & $0.88(0.55-1.39)$ & 0.588 & $0.48(0.22-1.02)$ & 0.058 & $1.03(0.63-1.68)$ & 0.880 \\
\hline $\begin{array}{l}\text { Undetermined due to two or more } \\
\text { causes identified }\end{array}$ & $1.11(0.71-1.76)$ & 0.628 & $0.61(0.25-1.50)$ & 0.286 & $1.35(0.79-2.32)$ & 0.269 \\
\hline $\begin{array}{l}\text { Undetermined due to negative } \\
\text { evaluation }\end{array}$ & $1.16(0.69-1.95)$ & 0.556 & $0.54(0.24-1.21)$ & 0.136 & $1.32(0.82-2.14)$ & 0.245 \\
\hline
\end{tabular}

$\mathrm{OR}$, odds ratio; $\mathrm{Cl}$, confidence interval; $\mathrm{AAs}$, aortic atheromas; CAPs, complex aortic plaques; $\mathrm{SAPS}$, simple aortic plaques.

${ }^{*} \mathrm{CAP}$ was not considered as large artery atherosclerosis component on TOAST classification; ${ }^{\dagger}$ No AAs as reference. 


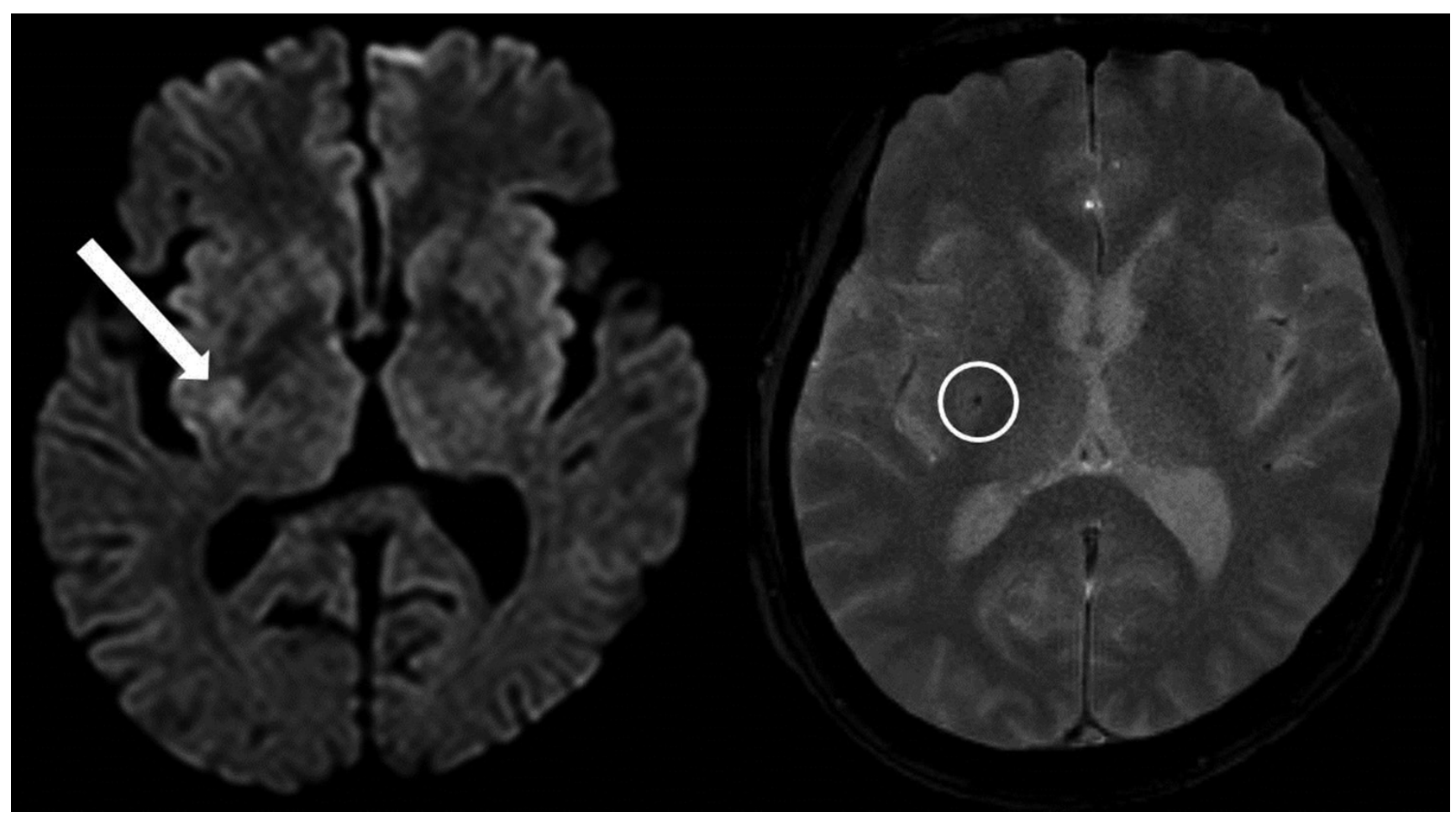

Supplementary Figure 1. Left arrow: acute infarction on the right basal ganglia in diffusion-weighted imaging. Right white ring: hemorrhagic transformation or cerebral microbleeds on gradient echo imaging. This hypointense lesion was not considered a cerebral microbleed because this area was overlapped with the acute infarction area. 


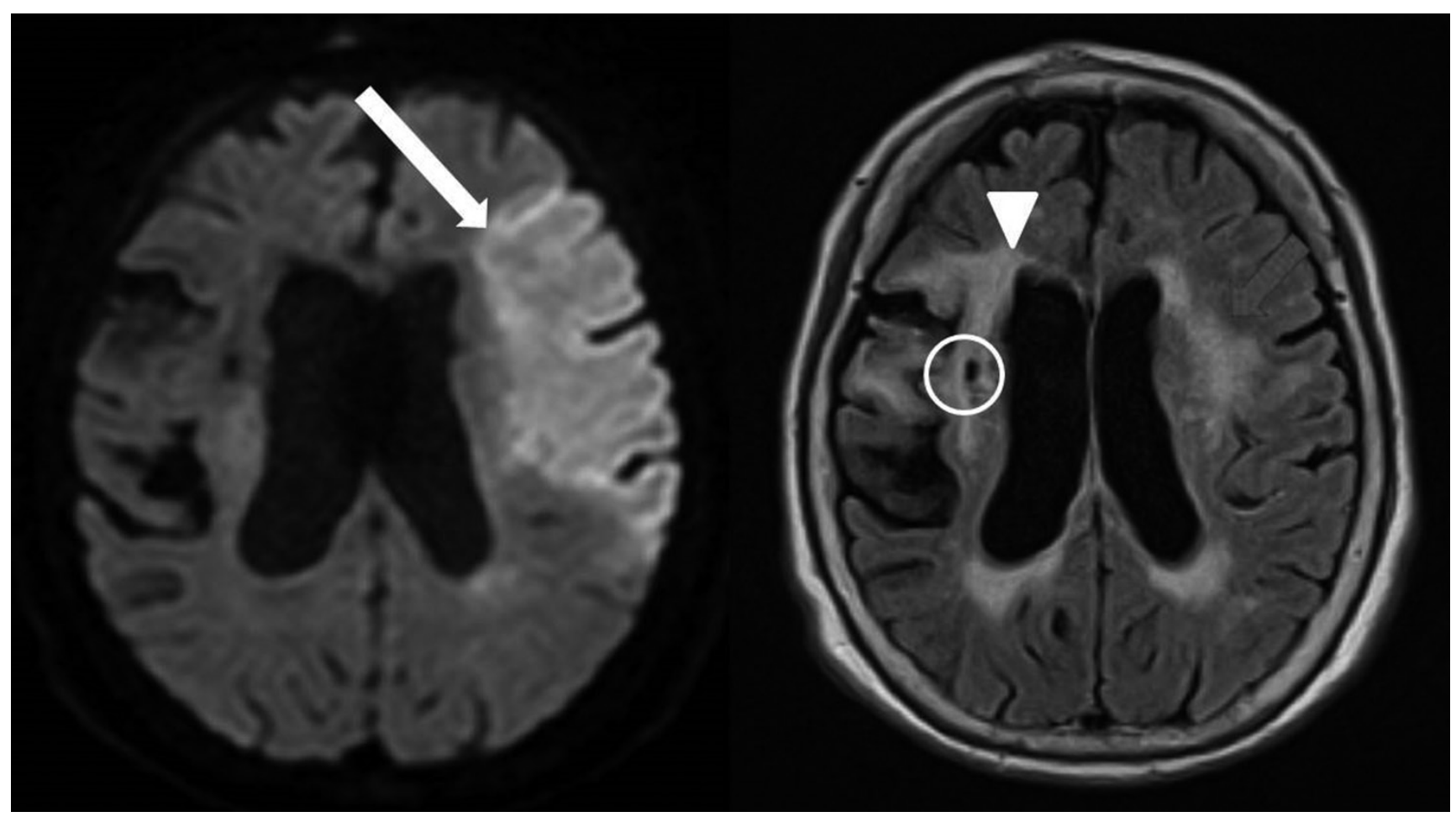

Supplementary Figure 2. Classification of white matter changes according to acute infarction. In patients with acute left middle cerebral artery territory infarction, the left side white matter changes were not classified as "white matter hyperintensity (WMH)" because this area was overlapped with the acute infarction area. In contrast, the right side white matter changes were regarded as high-grade periventricular WMH and a cavitary lesion on right side were classified as an asymptomatic lacunar infarction (ALI). 


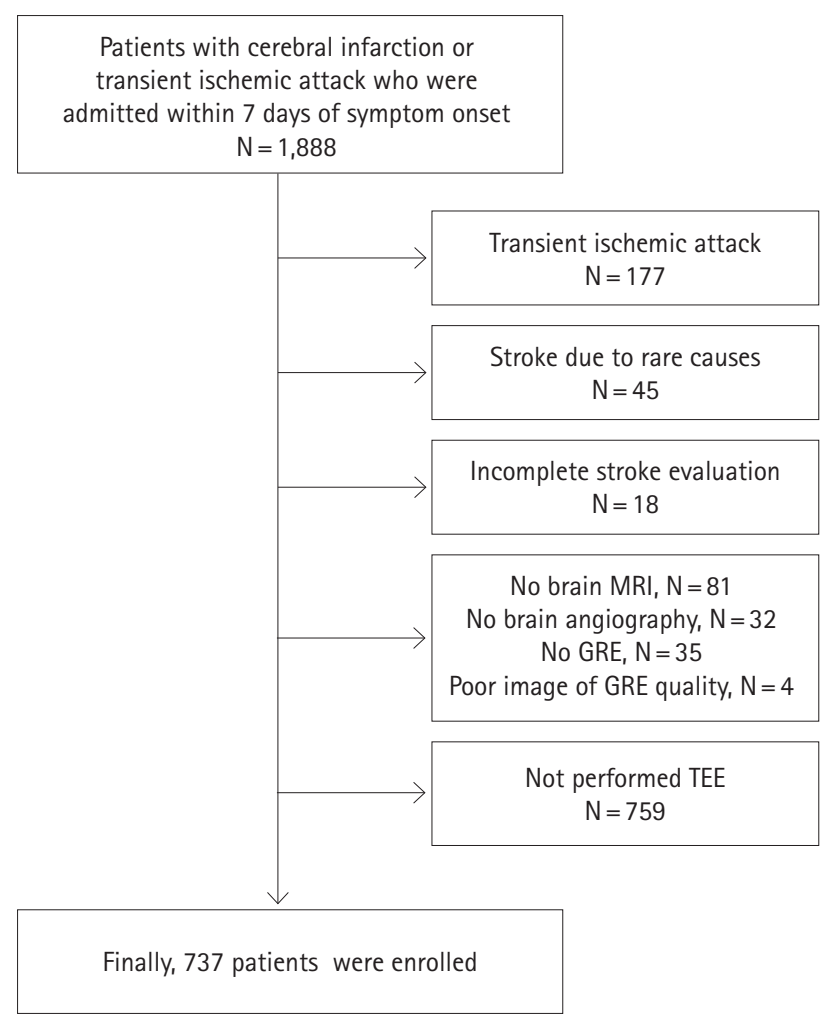

Supplementary Figure 3. Flowchart of participants according to inclusion and exclusion criteria. 